\title{
Hongos fitopatógenos asociados a la enfermedad de marchitez vascular y muerte regresiva en plantaciones de Tectona grandis L.f. (teca) en el Trópico Húmedo Ecuatoriano
}

\author{
(Phytopathogen fungi related to vascular wilt and die back in \\ Tectona grandis L.f (teak) field in Ecuadorian Tropical Rainforest)
}

Carlos Belezaca-Pinargote ${ }^{1,2 *}$, Edison Solano-Apuntes ${ }^{1}$, Rolando López-Tobar ${ }^{1}$, Renato Baque-Mite ${ }^{1}$, Adrián Ávila-Loor ${ }^{3}$, María Cóndor-Jiménez ${ }^{3}$, Tito Bohórquez-Barros ${ }^{2}$, Darío Dueñas-Alvarado

${ }^{1}$ Universidad Técnica Estatal de Quevedo, Carrera de Ingeniería Forestal, Quevedo, Ecuador. ${ }^{2}$ Universidad Técnica de Babahoyo, Carrera de Ingeniería Agropecuaria, Babahoyo, Ecuador.

${ }^{3}$ ENDESA - BOTROSA, Ecuador.

*Autor para correspondencia: cbelezaca@uteq.edu.ec

RECIBIDO: 04 de Diciembre de 2018

APROBADO: 19 de Febrero de 2019

DOI: $10.22370 /$ bolmicol.2018.33.2.1410

LOS AUTORES DECLARAN NO TENER CONFLICTO DE INTERESES

Palabras claves: Ceratocystis fimbriata; Fusarium sp.; incidencia; necrosis; severidad.

Key words: Ceratocystis fimbriata; Fusarium sp.; incidence; necrosis; severity.

\section{RESUMEN}

Plantaciones de teca (Tectona grandis L. f.) en Ecuador están siendo afectadas por una compleja enfermedad de marchitez vascular y muerte regresiva, con características epidémicas, sin que hasta el momento se conozca el o los agentes causales. Se planteó describir la sintomatología de la enfermedad e identificar los hongos fitopatógenos asociados a árboles enfermos en el Trópico Húmedo Ecuatoriano mediante morfofisiología. Se seleccionaron tres plantaciones de 2, 5 y 7 años de edad, en cada una se delimitó tres parcelas de $500 \mathrm{~m}^{2}$. Se realizó la descripción sintomatológica, evaluó la incidencia y severidad de la enfermedad empleando una escala de cinco categorías. Por parcela se di- seccionaron tres árboles, cuyos tejidos se llevaron al laboratorio, donde se emplearon tres estrategias metodológicas (cámara húmeda, sandwiches de zanahoria, y medio de cultivo papa-dextrosa-agar; PDA) para estimular la expresión de los fitopatógenos. En árboles enfermos se detectó clorosis, pérdida de turgencia, ápices de crecimiento secos, emisión de brotes epicormicos en el fuste, y marchitez fulminante. Se aisló e identificó Ceratocystis fimbriata Ellis \& Halst., y especies de Fusarium de forma consecutiva con las tres estrategias metodológicas empleadas. La incidencia de la enfermedad fue del $16.6 \%, 15.2 \%$, y $11.6 \%$ para las plantaciones de 2, 5 y 7 años, respectivamente. Los árboles enfermos en la plantación de 2 años se encontraron en las escalas 2, 4 y 5, mientras que en plantaciones 
de 5 y 7 años se ubicaron en las escalas 2, 3 y 5 de progreso de la enfermedad.

\begin{abstract}
Teak plantations (Tectona grandis L. f.) in Ecuador are being affected by a complex disease of vascular wilt and dieback, with epidemic characteristics, without knowing the causal agent(s) so far. We proposed to describe the symptomatology of the disease and identify phytopathogenic fungi associated with diseased trees in the Ecuadorian Humid Tropic by morphophysiology. Three plantations of 2, 5 and 7 years of age were selected, in each three plots of $500 \mathrm{~m}^{2}$ were delimited. The symptomatologic description was made, evaluated the incidence and severity of the disease using a scale of five categories. By plot, three trees were dissected, whose tissues were taken to the laboratory, where three methodological strategies were used (wet chamber, carrot sandwiches, and potatodextrose-agar culture medium, PDA) to stimulate the expression of phytopathogens. In diseased trees, chlorosis, turgor loss, dry growth apices, emission of epicormic shoots in the stem, and fulminating wilt were detected. It was isolated and identified Ceratocystis fimbriata Ellis \& Halst., and Fusarium species. consecutively with the three methodological strategies employed. The incidence of the disease was $16.6 \%, 15.2 \%$, and $11.6 \%$ for plantations of 2, 5 and 7 years, respectively. The sick trees in the plantation of 2 years were found in scales 2,4 and 5 , while in plantations of 5 and 7 years they were located in scales 2, 3 and 5 of progress of the disease.
\end{abstract}

\section{INTRODUCCION}

La especie forestal Tectona grandis L.f., comúnmente conocida como teca fue introducida a Ecuador en el año de 1950, procedente de Indochina. Sus inicios como plantación se dieron en la Estación Experimental Tropical Pichilingue (EETP), perteneciente al Instituto Nacional Autónomo de Investigaciones Agropecuarias (INIAP), ubicado en el cantón Quevedo, desde donde se originaron las primeras plantaciones comerciales en el litoral ecuatoriano ${ }^{1}$. La notable adaptación a las condiciones edafoclimáticas del medio, le permitieron convertirse en una especie de gran importancia económica y ecológica, debido a la calidad de su madera, rápido crecimiento y aportación de biomasa al suelo.

La superficie plantada con $T$. grandis en Ecuador aumentó significativamente durante las dos últimas décadas. Hasta el año 2004 existían entre 8000 y 12000 ha distribuidas en el país ${ }^{2}$, y para el año 2010 está superficie aumentó aproximadamente a 45000 ha $^{3}$, de las cuales 19812.60 ha fueron establecidas mediante el programa de incentivos forestales del estado ecuatoriano ${ }^{4}$, principalmente como plantaciones puras. Sin embargo, los árboles de teca como cualquier otra especie vegetal, son susceptibles al ataque de organismos fitopatógenos que pueden llegar a comprometer seriamente su sobrevivencia, causar un detrimento importante en la productividad, pérdidas de valor a productos y subproductos de la especie ${ }^{5,6}$.

Actualmente plantaciones de teca distribuidas en el Trópico Húmedo Ecuatoriano están siendo blanco de problemas fitosanitarios graves que ponen en riesgo la estabilidad de la especie en la región. Una enfermedad con características de marchitez vascular y muerte regresiva está matando miles de árboles de teca en pie, causando un detrimento prematuro del vigor y estado sanitario de los árboles. A simple vista los síntomas perceptibles incluyen decoloración del follaje, retraso en el crecimiento, copas pequeñas, y ramas muertas ${ }^{6}$.

Considerando las cuantiosas inversiones efectuadas en las plantaciones comerciales de teca, y la notoria afectación que están presentando, resulta necesario realizar un diagnóstico de los agentes biológicos presentes en árboles enfermos. Por tal motivo, se planteó describir la sintomatología de la enfermedad a nivel de campo, e identificar 
los microorganismos fungosos asociados a árboles enfermos de teca en plantaciones de la zona central del Trópico Húmedo Ecuatoriano (THE), como aporte fundamental al desarrollo forestal de la región y el país.

\section{MATERIALES Y MÉTODOS}

Área de estudio y establecimiento de parcelas. La investigación se realizó en tres plantaciones de teca de diferentes edades. La primera de 2 años, propiedad de la empresa GUAMANGUA S.A., situada en el cantón Buena Fe, provincia de Los Ríos, y las dos restantes de 5 y 7 años, pertenecientes al grupo empresarial SERAGROFOREST S.A., localizadas en el cantón Santo Domingo de los Tsáchilas, Provincia del mismo nombre, Ecuador. La densidad inicial y al momento de las evaluaciones fueron diferentes entre las plantaciones (Tabla 1). En cada plantación se delimitaron tres parcelas rectangulares de $500 \mathrm{~m}^{2}$.

Tabla 1. Densidad inicial y densidad detectada al momento de las evaluaciones en tres plantaciones de T. grandis con diferentes edades.

\begin{tabular}{cccc}
\hline No. & Plantación (edad) & $\begin{array}{c}\text { Densidad } \\
\text { plantación (árboles ha }^{-1} \text { ) }\end{array}$ & $\begin{array}{c}\text { Densidad al momento de } \\
\text { evaluación (árboles ha }^{-1} \text { ) }\end{array}$ \\
\hline 1 & 2 años & 1111 & 840 \\
\hline 2 & 5 años & 833 & 394 \\
\hline 3 & 7 años & 833 & 344 \\
\hline
\end{tabular}

Descripción sintomatológica, incidencia y severidad de la enfermedad. Dentro de cada parcela se realizó un censo árbol por árbol, con el propósito de establecer el número total de árboles presentes, la cantidad de árboles con síntomas de enfermedad, árboles muertos y aparentemente sanos. Los resultados obtenidos se introdujeron en la siguiente ecuación.

Incidencia $(\%)=\frac{\text { № de árboles enfermos }}{\text { Total de árboles }} * 100$

Para estimar la severidad de la enfermedad, se empleó una escala arbitraria de cinco categorías, que consideró las diferencias morfológicas visibles de ramas, hojas y fuste, y contrastó con árboles sanos (Tabla 2). Además, se realizó una descripción detallada de la sintomatología de la enfermedad, considerando diferencias morfológicas externas e internas entre árboles enfermos y sanos.
Tabla 2. Escala arbitraria empleada para la determinación de severidad de la enfermedad de marchitez vascular y muerte regresiva en plantaciones de teca.

\begin{tabular}{|c|c|}
\hline $\mathbf{N}^{\circ}$ & Criterio \\
\hline 1 & Árbol aparentemente sano \\
\hline 2 & Hojas terminales cloróticas \\
\hline 3 & Brotes de ramas muertas \\
\hline 4 & $50 \%$ de follaje muerto \\
\hline 5 & Árbol muerto o con el $80 \%$ de tejidos muertos \\
\hline
\end{tabular}

Recolección de tejidos necrosados a partir de árboles enfermos. En cada parcela de las plantaciones estudiadas se muestrearon 3 árboles $(7 \pm 0.5 \%)$ con síntomas de enfermedad, los mismos que fueron cortados al nivel del suelo con la ayuda de una motosierra. Con el propósito de encontrar evidencias de los lugares de ingreso y diseminación del o los fitopatógenos en los tejidos internos de árboles enfermos, se realizaron ins- 
pecciones en heridas naturales y de origen antropogénico (poda de ramas, cortes de machete, etc.) mediante cortes tangenciales y transversales en el fuste (cada $70 \mathrm{~cm}$ ).

Secciones de madera con evidencia de necrosis se seleccionaron, guardaron en bolsas plásticas, rotularon (fecha de recolección, procedencia, número de árbol, edad de la plantación, etc.) y trasladaron al Laboratorio de Microbiología Ambiental y Vegetal de la Universidad Técnica Estatal de Quevedo (UTEQ) para su posterior análisis fitopatológico.

\section{Aislamiento e identificación de hongos asocia- dos a tejidos de árboles enfermos. En el labora- torio, los tejidos necróticos fueron acondicionados y analizados mediante tres estrategias metodoló- gicas:}

- Cámara húmeda: Tejidos necrosados se introdujeron en bolsas plásticas conteniendo papel humedecido, e incubaron durante 96 horas a temperatura constante $\left(24 \pm 2{ }^{\circ} \mathrm{C}\right)$. Pasado este tiempo y con la asistencia de un estereomicroscopio, los tejidos se analizaron en busca de signos (micelio, cuerpos fructíferos, etc.) presentes ${ }^{7}$. Cuando se detectaron signos de microorganismos creciendo en la madera, estos se trasladaron al medio de cultivo papa-dextrosa-agar (PDA) al cual se le adicionó $0.2 \mathrm{~mL}$ de una mezcla de antibióticos $(50 \mu \mathrm{g} / \mathrm{mL}$ de penicilina y $25 \mu \mathrm{g} / \mathrm{mL}$ de estreptomicina), bajo condiciones de asepsia ${ }^{8}$.

- Siembra en sandwiches de zanahoria. Con el propósito de estimular la manifestación, de microorganismos fungosos de difícil desarrollo inicial en medio de cultivo PDA, se realizaron siembras con segmentos de tejidos necrosados de aproximadamente $2 \times 2 \times 0.5 \mathrm{~cm}$ (largo, ancho y espesor) entre dos rodajas de zanahoria, apreta- dos con cinta de papel, formando una especie de sándwiches ${ }^{9,10}$. Por cada árbol enfermo muestreado se formaron 10 sandwiches, e introdujeron en recipientes plásticos estériles $\left(1000 \mathrm{~cm}^{3}\right)$, taparon e incubaron durante 120 horas (5 días). Pasado el tiempo de incubación y con la ayuda de un estereomicroscopio, los sándwiches se analizaron en busca de signos (micelio, cuerpos fructíferos, etc.) presentes sobre la zanahoria, y cuando fueron detectados, se trasladaron a medio de cultivo PDA + antibióticos, bajo condiciones de asepsia ${ }^{8}$.

\section{- Siembras directas en medio de cultivo}

PDA. Con la ayuda de un cuchillo afilado se cortaron segmentos de madera de aproximadamente $0.5 \times 0.5 \mathrm{~cm}$, a partir de tejidos necróticos de cada árbol enfermo muestreado, y sin previa desinfección con ningún antiséptico, se sembraron cuatro pedacitos de madera necrótica en cinco placas de Petri conteniendo $10 \mathrm{~mL}$ de medio de cultivo PDA $+0.2 \mathrm{~mL}$ de una mezcla de antibióticos $(50 \mu \mathrm{g} /$ $\mathrm{mL}$ de penicilina y $25 \mu \mathrm{g} / \mathrm{mL}$ de estreptomicina $)^{8}$, y dejó incubar durante 96 horas a $24 \pm 2{ }^{\circ} \mathrm{C}$. Pasado este tiempo, los hongos desarrollados en el medio de cultivo se identificaron con la ayuda de claves taxonómicas ${ }^{11,12,13}$.

Análisis estadísticos. Los datos obtenidos a nivel de campo y laboratorio se analizaron empleando herramientas de estadística descriptiva. Para establecer si existían o no diferencia estadísticas significativas en la presencia (número de colonias) de hongos aislados, los datos se sometieron a un análisis de varianza (ANOVA) con un nivel de significancia de 95\% ( $\mathrm{P}<0.05)$, previa comprobación de los supuestos de normalidad y homocedasticidad de varianzas. Posteriormente se aplicó la prueba LSD (mínima diferencia significativa), con un nivel de significancia del 95\% $(\mathrm{P}<0.05)$. Para el efecto se empleó el paquete estadístico SYTAT 11 versión para Windows. 


\section{RESULTADOS}

Sintomatología de la enfermedad. En árboles de teca con estados iniciales de la enfermedad se observó decoloración (clorosis), y pérdida de turgencia en las hojas ubicadas en los extremos de ramas superiores. Posteriormente, conforme avanza la enfermedad, los ápices de crecimiento de las ramas mueren (se secan), y progresivamente desciende matándolas completamente. Cuando los árboles presentan esta sintomatología, disminuyen notoriamente su vigor frente a árboles sanos, debido a la pérdida de área fotosintética, lo cual estimula la emisión de numerosos brotes epicormicos en el fuste. Sin embargo, como la enfermedad continúa con su avance descendente, finalmente el árbol muere (se seca) en pie (Figura 1). Hay que destacar que, en árboles con estados iniciales de la enfermedad, generalmente no se observa la presencia de insectos barrenadores de corteza o/y madera, mientras que en el fuste de algunos árboles con estados avanzados de enfermedad se observan galerías de insectos justo en las zonas de transición entre madera sana y madera muerta.
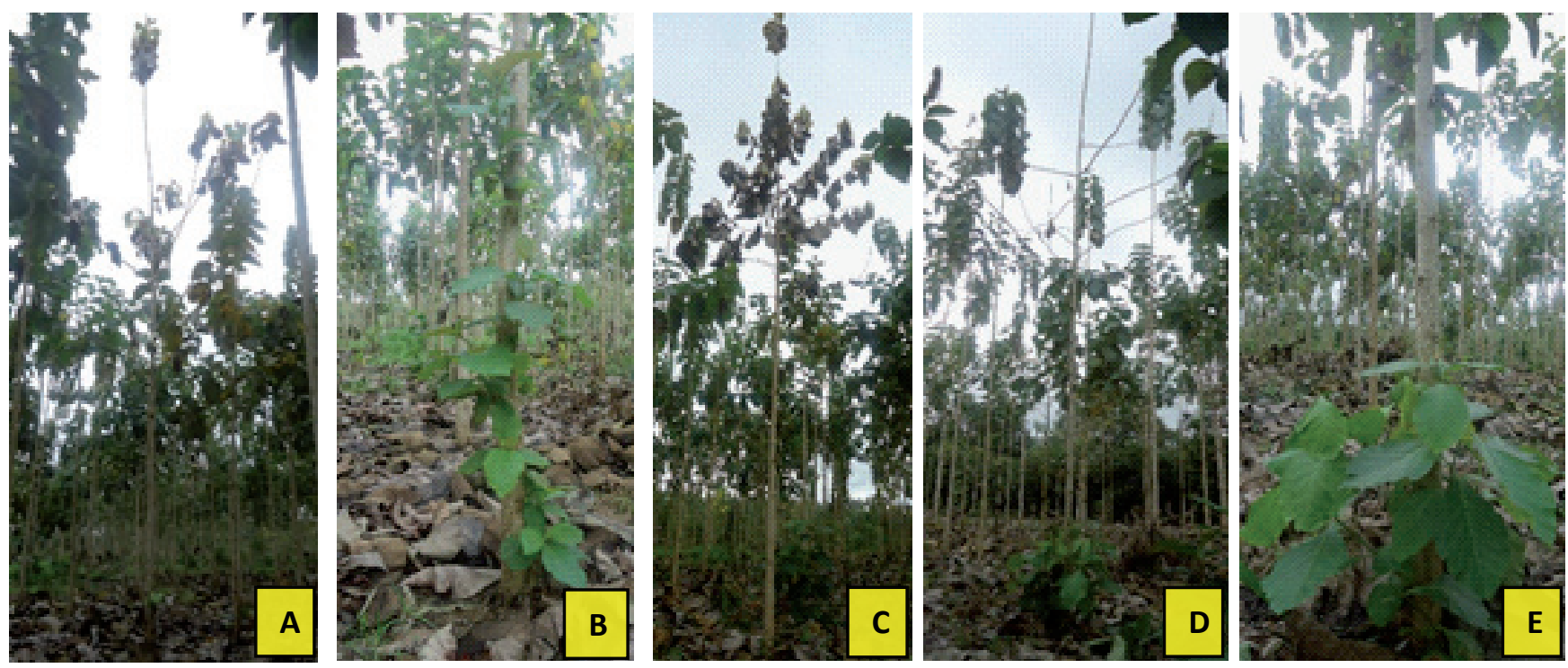

Figura 1. Evolución de la enfermedad de marchitez vascular y muerte regresiva en árboles de Teca: A $=$ Primeros síntomas caracterizados por clorosis en las hojas próximas a los ápices de crecimiento de ramas. $\mathrm{B}=$ Generación de múltiples brotes epicormicos en el fuste. $\mathrm{C}=$ Muerte del sistema foliar del árbol (marchitez vascular). $\mathrm{D}=$ Pérdida (defoliación) de las hojas secas. $\mathrm{E}=$ Brotes epicormicos basales empiezan a marchitarse (muerte total del árbol).

Al realizar cortes transversales en la base de los árboles (5 - $10 \mathrm{~cm}$ sobre el nivel del suelo), en la mayoría de casos no se observó síntomas de necrosis o taponamiento de los tejidos vasculares (Figura 2).

Sin embargo, al realizar cortes transversales a mayor altura $(50,70,100,150,200 \mathrm{~cm}$ sobre el nivel del suelo) quedan en evidencia los daños irreversibles ocasionados por el o los patógenos en los tejidos vasculares, necrosamiento y taponamiento de vasos conductores que impiden el normal flujo y reflujo de soluciones nutritivas y fotoasimilados (Figura 3).

Con el propósito de encontrar evidencias del mecanismo de ingreso del o los fitopatógenos en árboles enfermos, se realizaron inspecciones en heridas naturales y de origen antropogénico. Fue evidente que el ingreso del o los fitopatógenos se debió 
principalmente por heridas mecánicas de origen antropogénico, como podas de ramas y cortes accidentales con machetes cuando se realizaron actividades de control de malezas. En la mayoría de casos las heridas estaban cicatrizadas, sin embargo, protegían y enmascaraban el ingreso previo del patógeno, quien bajo la corteza se había diseminado tanto en sentido ascendente como descendente, pero principalmente hacia arriba, colonizando la madera de albura y duramen, ocasionado necrosamiento y taponamiento de los tejidos vasculares, que finalmente conllevan a la muerte del árbol. En algunas ocasiones las heridas no se encuentran cicatrizadas, sino expuestas, desde donde emanan constantemente fluidos de color café con olor astringente, características que indican al árbol como enfermo (Figura 4).
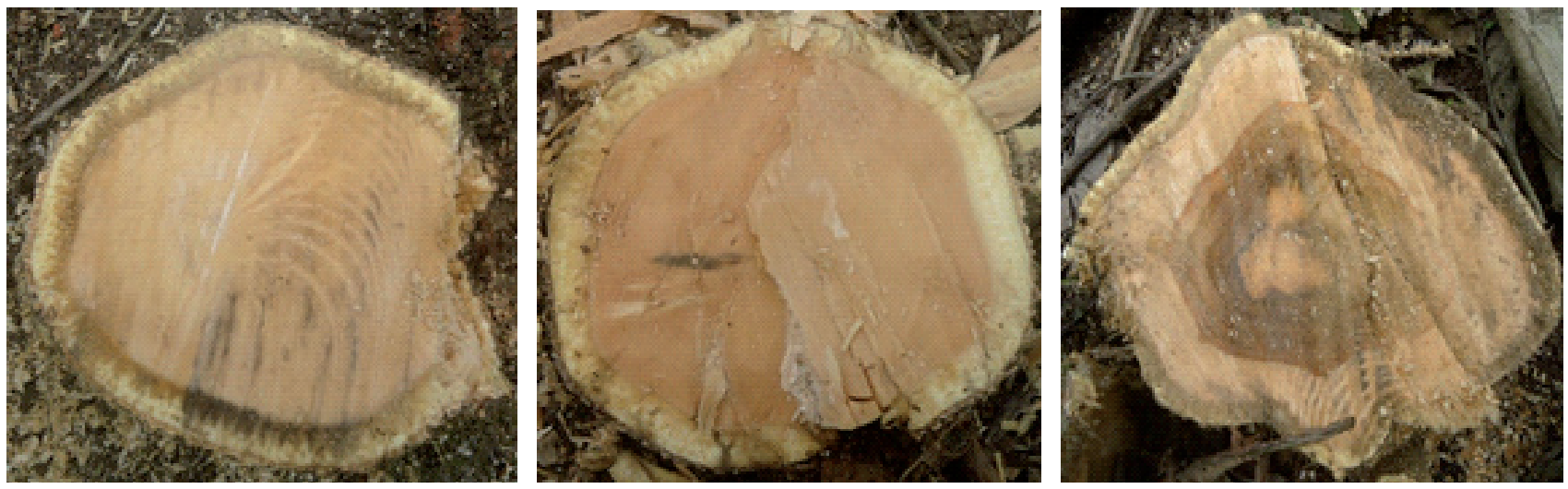

Figura 2. Cortes transversales en la base de árboles de teca enfermos $(5-10 \mathrm{~cm}$ sobre el nivel del suelo) muestran la ausencia de necrosis y daños vasculares. A y $\mathrm{B}=$ árboles de 2 años de edad, $\mathrm{C}=$ árbol de 7 años de edad.

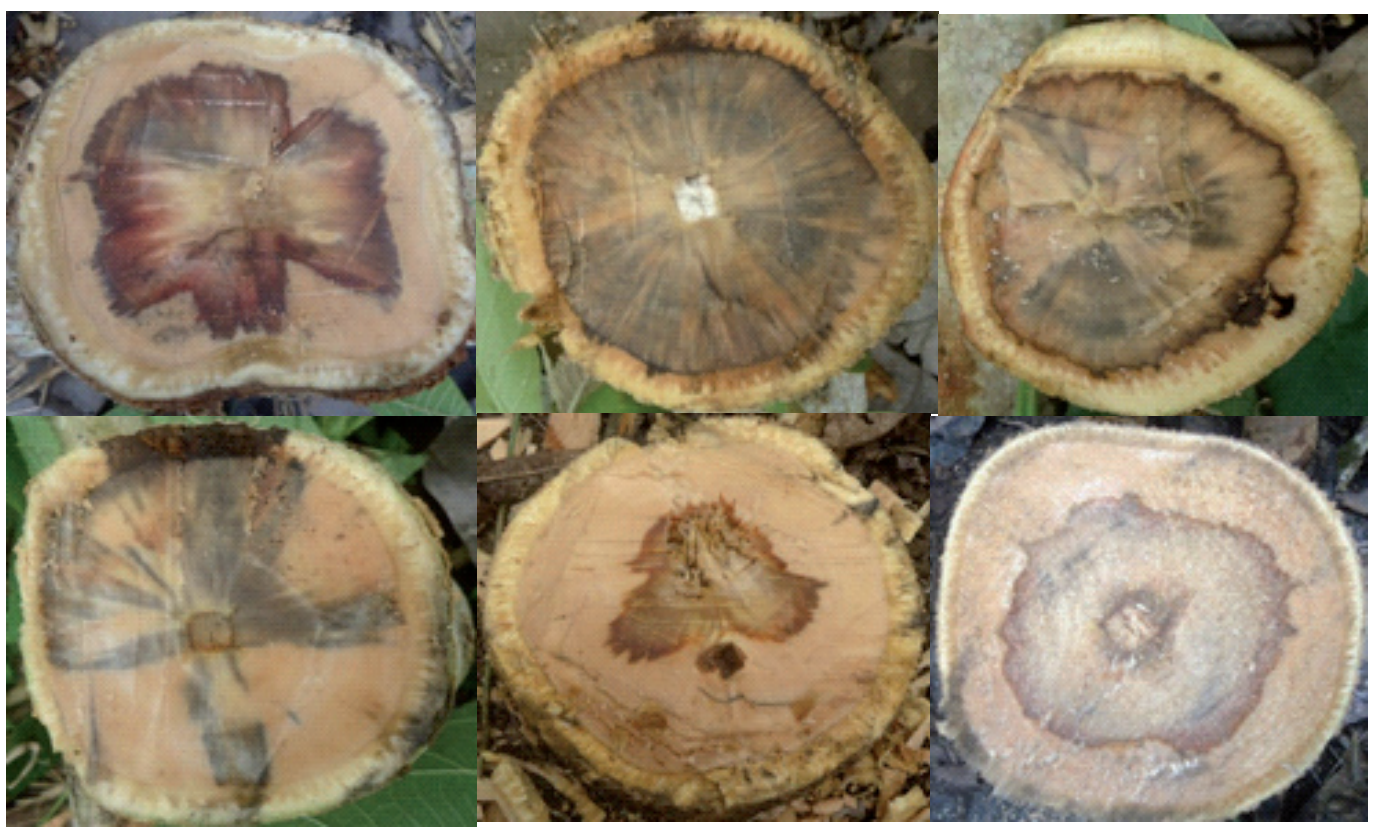

Figura 3. Diferentes tipos de daños detectados mediante cortes transversales en árboles de teca enfermos (sobre los $50 \mathrm{~cm}$ del nivel del suelo), evidenciando necrosis en la albura, duramen, y taponamiento de tejidos vasculares. 



Figura 4. Heridas naturales y mecánicas cicatrizadas y no cicatrizadas, como puntos de ingresos y posterior diseminación en tejidos vasculares del o los fitopatógenos asociados a la enfermedad de marchitez vascular y muerte regresiva de árboles de teca.

Incidencia y severidad de la enfermedad. En la plantación de 2 años de edad, se detectó en promedio 4 árboles enfermos, y 3 árboles muertos por parcela $\left(500 \mathrm{~m}^{2}\right)$, lo que permitió inferir la existencia de 80 árboles enfermos y 60 árboles muertos por ha ${ }^{-1}$. En las parcelas de la plantación de 5 años, en promedio se encontraron 2 árboles enfermos y 1 árbol muerto, lo que derivó en 40 árboles enfermos y 20 árboles muertos por ha-1. Mientras que, en la plantación de 7 años, se halló 1 árbol enfermo, y 1 árbol muerto en promedio por parcela, cuyos resultados representaron 20 árboles enfermos, y 20 árboles muertos por ha-1 ${ }^{-1}$ Estos resultados permitieron determinar que la incidencia de la enfermedad fue del 16.6\%, 15.2\%, y $11.6 \%$ para las plantaciones de teca de 2,5 y 7 años respectivamente (Tabla 3).

La mayor parte de árboles enfermos presentes en la plantación de 2 años, se encasillaron en las escalas 2 y 4 , lo cual indica que el 9.52\% de los árboles se encontraron con presencia de la enfermedad, en estado de progreso medio, y el $7.14 \%$ de los árboles están muertos en pie (escala 5). Mientras que, en las plantaciones de 5 y 7 años, los árboles enfermos se ubicaron en las escalas 2 y 3 , con el $10.15 \%$ y $5.81 \%$ de árboles afectados, $5.07 \%$ y $5.81 \%$ de árboles muertos (escala 5), respectivamente (tabla 4). 
Tabla 3. Número de árboles aparentemente sanos, enfermos, muertos por ha ${ }^{-1}$, e incidencia de la enfermedad de muerte regresiva y marchitez vascular en tres plantaciones de $T$. grandis de diferentes edades en el Trópico Húmedo Ecuatoriano. Valores representan el promedio de tres repeticiones, con su respectivo error estándar.

\begin{tabular}{cccccc}
\hline $\begin{array}{c}\text { Plantación } \\
\text { (edad) }\end{array}$ & $\begin{array}{c}\text { Árboles ha-1 } \\
\text { (Densidad) }\end{array}$ & $\begin{array}{c}\text { Arboles aparentemente } \\
\text { sanos ha }^{-1}\end{array}$ & $\begin{array}{c}\text { Árboles } \\
\text { enfermos ha-1 }^{-1}\end{array}$ & $\begin{array}{c}\text { Árboles } \\
\text { muertos ha-1 }^{-1}\end{array}$ & $\begin{array}{c}\text { Incidencia } \\
\mathbf{( \% )}^{*}\end{array}$ \\
\hline 2 años & 840 & $700 \pm 0.88$ & $80 \pm 0.33$ & $60 \pm 1.20$ & $16.6 \pm 2.08$ \\
\hline 5 años & 394 & $334 \pm 0.57$ & $40 \pm 0.57$ & $20 \pm 0.10$ & $15.2 \pm 2.74$ \\
\hline 7 años & 344 & $304 \pm 1.33$ & $20 \pm 0.33$ & $20 \pm 0.33$ & $11.6 \pm 0.83$ \\
\hline
\end{tabular}

* Incluye árboles enfermos y muertos

Tabla 4. Severidad de la enfermedad de marchitez vascular y muerte regresiva por ha-1, en plantaciones de $T$. grandis de 2, 5 y 7 años de edad, ubicadas en el Trópico Húmedo Ecuatoriano.

\begin{tabular}{ccccccc}
\hline \multirow{2}{*}{$\begin{array}{c}\text { Plantación } \\
\text { (edad) }\end{array}$} & $\begin{array}{c}\text { Árboles ha-1 } \\
\text { (Densidad) }\end{array}$ & $\mathbf{1}$ & $\mathbf{2}$ & $\mathbf{3}$ & $\mathbf{4}$ & $\mathbf{5}$ \\
\cline { 3 - 7 } & 840 & 700 & 40 & 0 & 40 & 60 \\
\hline $\mathbf{2}$ años & 394 & 334 & 20 & 20 & 0 & 20 \\
\hline $\mathbf{5}$ años & 344 & 304 & 10 & 10 & 0 & 20 \\
\hline 7 años & & & & &
\end{tabular}

Variables Dasométricas. El comportamiento dasométrico de los árboles de teca en las tres plantaciones evaluadas, estuvo determinado por la edad, y para cada una de ellas un crecimiento uniforme. Las alturas y diámetros (DAP) promedio se incrementaron con la edad, donde aquella de 2 años presentó $11.4 \mathrm{~m}$, y $10.1 \mathrm{~cm}$ (altura y DAP), mientras que las plantaciones de 5 y 7 años mostraron $16.4 \mathrm{~m}$, y $16.9 \mathrm{~cm} ; 18.2 \mathrm{~m}$, y $20.1 \mathrm{~cm}$ (altura y DAP), respectivamente (tabla 5).
Microorganismos fungosos en tejidos de árboles enfermos. Se determinó que en el 100\% de las muestras de tejidos leñosos necrosados, procedentes de árboles enfermos de T. grandis, e incubados en cámara húmeda, existía la presencia de cuerpos fructíferos globosos de color negro, correspondientes a peritecios, que cubrían las áreas necróticas de la madera. Por otra parte, los sandwiches de zanahoria conteniendo tejidos necrosados, mostraron presencia de micelio algodonoso y la

Tabla 5. Alturas y DAP (máximos, medios y mínimos) obtenidos en tres plantaciones de T. grandis de 2, 5 , y 7 años de edad, afectadas por la enfermedad de marchitez vascular y muerte regresiva en el Trópico Húmedo Ecuatoriano. Valores representan el promedio de tres parcelas con su respectivo error estándar.

$\begin{array}{ccccc}\begin{array}{c}\text { Plantación } \\ \text { (edad) }\end{array} & \begin{array}{c}\text { Árboles ha-1 } \\ \text { (Densidad) }\end{array} & \begin{array}{c}\text { No. árboles } \\ \text { por parcela }\end{array} & \text { Altura (m) } & \text { DAP (cm) }\end{array}$

\begin{tabular}{cccccccccc}
\hline & & & Máxima & Media & Mínima & Máximo & Medio & Mínimo \\
\hline 2 años & 840 & 42 & 13.5 & $11.4 \pm 0.20$ & 6.8 & 13.3 & $10.1 \pm 0.25$ & 7.2 \\
\hline 5 años & 394 & 20 & 16.8 & $16.4 \pm 0.27$ & 15.9 & 17.8 & $16.9 \pm 0.33$ & 15.1 \\
\hline 7 años & 344 & 17 & 18.5 & $18.2 \pm 0.37$ & 17.9 & 20.4 & $20.1 \pm 0.35$ & 19.5 \\
\hline
\end{tabular}


formación de peritecios en el 100\% de los árboles enfermos, para todas las plantaciones estudiadas. Finalmente, las siembras de pedacitos de madera necrosada en medio de cultivo PDA, dieron como resultado colonias fúngicas color negro $\mathrm{y}$ presencia de peritecios globosos con un cuello extendido, en cuyo extremo superior poseían varios apéndices (fimbrias), donde se acumulaban masas circulares de ascosporas de color amarillo pálido. Los peritecios del hongo después de 120 horas de incubación en medio de cultivo PDA, presentaron una coloración hialina (peritecios jóvenes), marrón (conforme van madurando), y negro cuando están completamente maduros, una base globosa, cuello alargado claramente visible con longitudes entre 800-900 $\mu \mathrm{m}$, presencia de fimbrias en el extremo superior del cuello que rodean al ostiolo. Sobre las fimbrias son distinguibles masas de apariencia hialina o cremosa, constituidas por ascosporas maduras liberadas por lisis de las ascas al interior del peritecio. Las ascosporas son unicelulares (no septadas), hialinas, tienen forma elíptica, con apariencia de sombrero, y dimensiones de 4-8 x 2-5 $\mu \mathrm{m}$. Estas características permitieron identificar al hongo como Ceratocystis fimbriata Ellis \& Halst., mientras que colonias de color blanco correspondieron al hongo Fusarium spp.

Se detectaron diferencias estadísticas significativas en la frecuencia de aparición (número de colonias) de colonias fúngicas aisladas en el medio de cultivo PDA, a partir de tejidos necrosados de árboles enfermos, en todas las plantaciones estudiadas, donde $C$. fimbriata, fue el hongo que presentó el mayor número de colonias, mientras que las especies de Fusarium mostraron menor presencia. Para la plantación de dos años de edad ( $\mathrm{F}=9.03 ; \mathrm{P}=0.008)$, se obtuvieron en promedio 12 colonias de $C$. fimbriata y 8 de Fusarium spp., mientras que en las plantaciones de 5 años $(\mathrm{F}=38.9 ; \mathrm{P}=0.000)$, y 7 años $(\mathrm{F}=37.8 ; \mathrm{P}=0.000)$ se obtuvo 13 y 7 colonias de C. fimbriata y Fusarium sp., respectivamente (tabla 6).

Tabla 6. Número de colonias de C. fimbriata y Fusarium spp. aislados a partir de árboles de T. grandis con síntomas de marchitez vascular y muerte regresiva en tres plantaciones del Trópico Húmedo Ecuatoriano. Valores corresponden al promedio de colonias obtenidas por cada árbol, con su respectivo error estándar.

\begin{tabular}{cccc}
\hline Fitopatógenos & $\begin{array}{c}\text { Hda. CANBIOSCA } \\
\text { Plantación 2 años de edad }\end{array}$ & $\begin{array}{c}\text { Hda. LA PALMA } \\
\text { Plantación 5 años de edad }\end{array}$ & $\begin{array}{c}\text { Hda. LA PALMA } \\
\text { Plantación 7 años de edad }\end{array}$ \\
\hline C. fimbriata & $12 \pm 0,88 \mathbf{a}$ & $13 \pm 0,65 \mathbf{a}$ & $13 \pm 0,74 \mathbf{a}$ \\
\hline Fusarium spp. & $8 \pm 0,88 \quad$ b & $7 \pm 0,65 \quad$ b & $7 \pm 0,74 \quad$ b \\
\hline Total colonias & 20 & 20 & 20 \\
\hline
\end{tabular}

\section{DISCUSIÓN}

Hasta la década de 1990, las pocas plantaciones de T. grandis existentes en el Trópico Húmedo Ecuatoriano (THE) no presentaban problemas sanitarios significativos por lo que la especie era considerada altamente resistente a las duras condiciones ecológicas de la región. No obstante, para finales de la primera década de los años 2000 con el aumento de la superficie plantada este escena- rio cambió, reportándose los primeros problemas fitosanitarios 5 . En Patología Forestal es conocido el principio que, una vez masificadas las plantaciones monoespecíficas, la aparición de problemas fitosanitarios ocasionados por microorganismos patógenos es cuestión de tiempo, y teca no es la excepción. La enfermedad de marchitez vascular y muerte regresiva de la teca, presenta una extraña y compleja sintomatología parecida a la detectada en otras especies forestales tropicales promisorias 
de la región, como en Schizolobium parahybum ${ }^{14}$, Acrocarpus fraxinifolius ${ }^{15}$, que asolaron plantaciones entre las décadas de 1990 y 2000 , ocasionado pérdida de inversiones y desplazando a estas especies de los sistemas productivos del THE, sin que se las vuelva a considerar en nuevos planes o programas de forestación y reforestación.

La respuesta de los árboles de teca a la enfermedad es variable, en algunos casos la clorosis, pérdida turgencia, defoliación, muerte descendente de ramas, y presencia de fluidos desde heridas es lento, gradual, y heterogéneo. En otros casos la enfermedad resulta letal y fulminante para los árboles susceptibles, que en cuestión de horas pasan de estar aparentemente sanos a marchitarse totalmente. Sin embargo, es de destacar que en las plantaciones del THE existen árboles a quienes la enfermedad parece no ejercer mayores daños, lo que hace sospechar la presencia de individuos con aceptables niveles de tolerancia/resistencia frente a la enfermedad. Este comportamiento obedecería a la variabilidad genética, propia de individuos obtenidos a partir de semillas de libre polinización ${ }^{16}$, que pueden ser aprovechados en futuros programas de mejoramiento de la especie.

De acuerdo a las evidencias obtenidas, parece ser que el o los fitopatógenos ingresan a los árboles de teca a través de heridas mecánicas, provocadas por podas de ramas o brotes epicórmicos, y lesiones generadas por machetes durante labores culturales de limpieza de malezas, que no fueron protegidas con antifúngicos, sin embargo, no hay que descartar factores abióticos como el viento, que pueden generar microlesiones en la base de árboles por torceduras, fustes, tejidos jóvenes y suculentos de ramas que pueden ser empleadas como puertas de ingreso, fácilmente colonizados por hongos fitopatógenos ${ }^{17}$.

La ausencia de insectos barrenadores de corteza o/y madera, o de galerías en árboles con estados iniciales de la enfermedad, parecería indicar que los insectos tendrían un papel secundario en el inicio de la infección, y más bien su aparición en áreas de transición entre madera sana y madera muerta en individuos con niveles avanzados de la enfermedad, obedecería que los insectos son atraídos a árboles debilitados o moribundos, cuyos flujos de savia están ralentizados o ausentes, y son incapaces de producir sustancias toxicas contra los insectos que podrán desarrollarse favorablemente en su interior. Probablemente los árboles enfermos de teca difunden en el aire compuestos químicos volátiles, diferentes a los emitidos por árboles sanos, que pueden ser detectados a grandes distancias por insectos en vuelo y los induce encaminarse hacia el árbol emisor. Este tipo de fenómeno ya ha sido reportado en otras latitudes y especies leñosas como Ulmus spp..$^{18,19}$, Quercus rubra, Acacia mearncii, Pinus spp. Eucaliptus spp. y Theobroma cacao $^{20}$, afectadas por hongos Ophiostomatales que conducen a enfermedades de marchitez vascular. $\mathrm{O}$ en su defecto los insectos son atraídos por sustancias volátiles como los sesquiterpenos producidos por los propios hongos fitopatógenos ${ }^{21}$.

La incidencia de la enfermedad en las tres plantaciones (16.6\%, $15.2 \%$, y $11.6 \%)$, si bien podría considerarse moderada, constituye una alerta sobre los daños que puede generar a la industria nacional de la teca, si no se consideran estrategias de prevención y manejo silvícola adecuados. La mayor parte de árboles enfermos se encontraron en estado medio de progreso de la enfermedad, pero es cuestión de tiempo para que mueran, aunque el tiempo de evolución desde que el o los fitopatógenos ingresan a los árboles a nivel de campo, hasta que se manifiestan los primeros síntomas y posterior muerte del árbol, aún no está claro.

La presencia de C. fimbriata y Fusarium spp. asociados a tejidos necrosados de árboles enfermos de $T$. grandis, pone de manifiesto el riesgo 
al que están expuestas las plantaciones de esta especie forestal en el THE, ya que ambos microorganismos fungosos son altamente fitopatogénicos y han estado asociados como causantes de enfermedades en especies leñosas en Ecuador y otras regiones del planeta. $C$. fimbriata ha estado asociado enfermedades en Theobroma cacao en Latinoamérica ${ }^{20}, A$. fraxinifolius en Ecuador ${ }^{15}$, Eucaliptus spp. en Brasi1 ${ }^{22}$, mientras que Fusarium spp. han sido reportados ocasionando daños a plantaciones de Gmelina arborea en Costa $\mathrm{Rica}^{23,24}, \mathrm{Pi}$ nus radiata en España ${ }^{25}$, etc.

\section{CONCLUSIONES}

A pesar de haberse detectado la presencia de dos microorganismos fungosos altamente fitopatogénicos (C. fimbriata y Fusarium spp.) asociados a árboles enfermos de teca, aún no se puede asegurar si la enfermedad de marchitez vascular y muerte regresiva es ocasionada por alguno de ellos, o si actúan en sinergia, por lo que se hace necesario realizar pruebas de patogenicidad (Postulados de Koch). La ausencia de insectos barrenadores corteza o/y madera en los árboles evaluados, podría indicar que no son causantes de las infecciones, y que su función sería secundaria en el proceso de la enfermedad. Finalmente, debido a que la identificación de los microorganismos estuvo basada en morfología, se deberían efectuar estudios moleculares con el propósito de realizar una caracterización más precisa de los posibles fitopatógenos causantes.

\section{AGRADECIMIENTOS}

Al proyecto de investigación PFOC 5-212017 "Determinación de problemas fitosanitarios presentes en plantaciones de teca (Tectona grandis) de las provincias Santo Domingo de Los Tsáchilas, Los Ríos, Guayas y Esmeradas. También se agradece a las empresas SERAGROFOREST S.A. y GUAMANGUA S.A. que permitieron realizar estudios en sus plantaciones.

\section{REFERENCIAS}

1. Nieto J, Hernández S, Motte E, Mayek N. Análisis de la diversidad genética del germoplasma de Teca (Tectona grandis L.f.) en el Ecuador. Rev. Mex. Cienc. Forestales. 2014; 5(21):108121. http://www.scielo.org.mx/pdf/remcf/v5n21/ v5n21a8.pdf

2. Bhat KM, Ok Ma H. Perspectiva para la teca de plantaciones. Actualidad Forestal Tropical. 2004; 12(1):1-5. https://docplayer.es/30461071-Perspectivas-para-la-teca-de-plantaciones-durante-siglosla-teca-ha-sido-la-reina-de-las-maderas-por-suscaracteristicas.html

3. Kolert W, Cherubini L. Teak resources and marked assessment 2010 (Tectona grandis Linn. F.). Food and Agriculture Organization of the United Nations. Forestry Department. Planted Forest and Trees Working Papers Series FP/47/E FAO,
Rome, Italy. 2012; 42 p. http://www.fao.org/3/aan537e.pdf

4. MAGAP (Ministerio de Agricultura, Ganadería, Acuacultura y Pesca). Programa de incentivos para la reforestación con fines comerciales. Guayaquil, Ecuador. 2016; 71 p.

5. Flores T, Crespo R, Cabezas F. Plagas y enfermedades en plantaciones de Teca (Tectona grandis L. f.) en la zona de Balzar, provincia del Guayas. Ciencia y Tecnología. 2010; 3(1): 15-22. http://revistas.uteq.edu.ec/index.php/cyt/article/view/41

6. Ávila-Loor AA. Identificación de microorganismos fungosos asociados a la enfermedad de muerte regresiva en plantaciones de Tectona grandis L.F. (teca) en la zona central del Trópico Húmedo Ecuatoriano. Proyecto de Investigación de Ingeniero 
Forestal. Universidad Técnica Estatal de Quevedo, Ecuador. 2016. 63 p.

7. CMI (Commonwealth Mycological Institute). Plant pathologist's Pocketbook. London. England. $1983 ; 267$ p.

8. Parkinson D. Filamentous fungi. In Weaver R, Angle S, Bottomley P, Bezdicek D, Smith S, Tabatabai A, Wollum A. (eds). Methods of Soil Analysis. Part 2, Microbiological and Biochemical Propeties. Number 5 in Soil Science Society of America Book Series. Soil Science Society of America. Inc., Madison, Wisconsing, USA. 1994; $329-350 \mathrm{p}$.

9. Li J, Zhang Y, Xu KC, Yang JY, Han YH, Sun YX, et al. First report of wilt of Eucalyptus caused by Ceratocystis fimbriata in China. Plant Disease. 2014; 98(12): 1744. https://apsjournals.apsnet.org/ doi/10.1094/PDIS-06-14-0580-PDN

10. Piveta G, Ferreira MA, Muniz M, Valdetaro D, Valdebenito-Sanhueza $\mathbf{R}$, Harrington $\mathbf{T}$, Alfenas AC. Ceratocystis fimbriata on kiwifruit (Actinidia spp.) in Brazil. N. Z. J. Crop Hortic. Sci. 2016; 44: 13-24. http://www.public.iastate. edu/ tcharrin/Grazi_NZJCHS.pdf

11. Von Arx JA. The genera of fungi sporulating in pure culture. Ed. Cramer J. Alemania. 1981; 424 p.

12. Barnett H, Hunter B. Illustrated genera of Imperfect fungi Macmillan Publishing Company. Fourth Edition. USA. 1987; 218 P.

13. Hanlin R. Illustrated genera of Ascomycetes. APS. PRESS. The American Phytopathological Society. St. Paul, Minnesota. 1992; p 18 - 20; $48-49$.

14. Belezaca C, Suárez C, Vera D. Hongos fitopatógenos asociados a la enfermedad de muerte regresiva y pudrición del fuste de pachaco (Schizolobium parahybum) en el Trópico Húmedo Ecuatoriano. Boletín Micológico. 2011; 26(1): 15-22. https://revistas.uv.cl/index.php/Bolmicol/article/ view/895/872

15. Belezaca C, Mora W, Prieto O, Cedeño P, Moran J, Valenzuela E. Hongos asociados a problemas fitosanitarios emergente en especies forestales de importancia económica del Trópico Húmedo Ecuatoriano. In Libro de resúmenes del XXI Congreso de la Sociedad Chilena de Fitopatología. Puerto Varas, Chile (17 - 19 de octubre del 2012). 2012; p 79.

16. Bräutigam $K$, Vining $K$, Lafon-Placette $C$, Fossdal C, Mirouze M, Gutiérrez-Marcos J, et al. Epigenetic regulation of adaptive responses of forest tree species to the environment. Ecol. Evol. 2013; 3(2):399-415. https://www.ncbi.nlm.nih. gov/pubmed/23467802

17. Nkuekam GK, Solheim H, Beer ZW, Grobbelaar JW, Jacobs K, Winfield MJ. et al. Ophiostoma species, including Ophiostoma borealis sp. nov., infecting wounds of native broadleaved trees in Norway. Cryptogam. Mycol. 2010; 31(3): 285-303. https://repository.up.ac.za/handle/2263/16486

18. Martin D, García-Vallejo MC, Pajares JA, López D, Díez JJ. Elm bark components and their potential influence on bark beetle feeding. Invest Agrar. Sist Recur For. 2004; 13(1): 227-235. http:// revistas.inia.es/index.php/fs/article/view/827

19. Faccoli M, Santini A. Dutch elm disease and elm bark beetles: Pathogen-Insect Interaction. In Vector-mediated transmission of plant pathogens. Chapter: 6. Eds. Brown JK. The American Phytopathological Society. 2016; 86 p. ISBN: 978-089054-535-5. 
20. Harrington TC. Ceratocystis diseases. In Infectious Forest Diseases. Eds. Gonthier P, Nicolotti G. CABI. 2013; 230-255 p. ISBN: 13-978178064-0402.

21. Kramer R, Wolf-Rainer A. Volatile sesquiterpenes from fungi: what are they good for?. Phytochem. Rev. 2012; 11(1): 15-37. https://link.springer.com/article/10.1007/s11101-011-9216-2

22. Ferreira MA, Harringtong TC, Alfenas AC, Mizubuti ES. Movement of genotypes of Ceratocystis fimbriata within and among Eucalyptus plantations in Brazil. Phytopathology. 2011; 101(8):1005-1012. https://www.ncbi.nlm. nih.gov/pubmed/21486144

23. Arguedas M. Problemas fitosanitarios de la melina (Gmelina arborea (Roxb)) en Costa Rica.
Kuru Revista Forestal. 2004; 1-9. http://revistas. tec.ac.cr/index.php/kuru/article/view/574/500

24. Murillo-Gamboa O, Salas-Rodríguez A, Murillo-Cruz R, Ávila-Arias C. Tasa de avance de la pudrición del tronco en melina Gmelina arborea Roxb. y posibilidades de manejo. Revista Forestal Mesoamericana Kuru, 2016; Volumen especial: 40-50. http://revistas.tec.ac.cr/index.php/ kuru/article/view/2551

25. Hernández-Escribano L, Iturritxa E, Aragonés A, Mesanza N, Berbegal M, Raposo $\mathrm{R}$, et al. Root infection of canker pathogens, Fusarium circinatum and Diplodia sapinea, in asymptomatic trees in Pinus radiata and Pinus pinaster plantations. Forest. 2018; 128(9): 1-15. https://www. mdpi.com/1999-4907/9/3/128 